\title{
sciendo
}

\section{Evaluation of Antibiotic Prescribing Patterns in Paediatric Dental Patients: Cross - Sectional Epidemiological Study}

\section{SUMMARY}

Background/Aim: The purpose of this study was to investigate the antibiotic prescribing patterns for the treatment of paediatric oral infection, dental trauma and prophylaxis among dentists in Turkey. Material and Methods: A total of 206 paediatric dentists, including general dentists, paediatric dentists and specialist dentists, participated in this crosssectional study. The questionnaire included questions about the number of paediatric patients treated and antibiotics prescribed, the most commonly prescribed antibiotic for oral infections and the clinical conditions under which antibiotics were prescribed. The participants' ages, workplaces and professional experience were also evaluated. Results: The majority of the participants were paediatric dentists (45.1\%) and general dentists $(42.7 \%)$. For the management of dental infections, most dentists prescribed penicillin (94.7\%). Their foremost prescription choices for the presence of an anaerobic infection were metronidazole (48.5\%) and penicillin (32\%). For dental trauma, the most common antibiotic-prescribed cases were avulsion and contaminated wounds, followed by alveolar fracture. Antibiotics were prescribed as a first choice for dental infections and dental infections of anaerobic origin, with no significant differences between professional experience or dental specialty in the dentists $(p>0.05)$. Practitioners belonging to Ministry of Health dental centres significantly differed from all other groups in preferring the antibiotic cephalosporin for dental infections of anaerobic origin. Conclusions: Adherence to published guidelines for antibiotic prescriptions for anaerobic dental infections and dental trauma was low. Clearer, more specific guidelines and increased post-graduate education could lead to a reduction in the negative consequences of this issue's resultant over-prescribed antibiotics.

Keywords: Antibiotics, Clinical Protocols, Guidelines
Tugba Yigit ${ }^{1}$, Sibel Ezberci ${ }^{1}$, Burcu Gucyetmez Topal $^{2}$

${ }^{1}$ Department of Pediatric Dentistry, Faculty of Dentistry, Usak University, Usak, Turkey

${ }^{2}$ Department of Pediatric Dentistry, Faculty of Dentistry, Afyonkarahisar Health Sciences University, Afyonkarahisar, Turkey

Balk J Dent Med, 2021;122-128

\section{Introduction}

Antibiotics are the most commonly used medications for the treatment and prevention of bacterial infections ${ }^{1}$. Using antibiotics can decrease infection time and reduce the risk of bacteraemia ${ }^{2}$. However, the widespread use of antibiotics has allowed certain bacteria to develop resistance. Indeed, antibiotics resistance is increasing worldwide ${ }^{1}$.
The Centers for Disease Control and Prevention (CDC) reported having 140,000 emergency applications every year due to antibiotic reactions, which are the most common causes of emergency visits for adverse drug events in paediatric patients ${ }^{3}$. Pallasch told that antibiotics help a host's immune system gain control and eliminate the infection but, in addition, they have many negative outcomes, such as toxicity, allergy, superinfection, chromosomal mutations, gene transfer to vulnerable organisms and the expression of dormant resistant genes ${ }^{4}$. 
Dentists prescribe the third highest number of antibiotics in the nation by volume 5 , or $7-11 \%$ of all common antibiotics ${ }^{6}$. The essential factor in the distinction between medical and dental conditions is that most dental infections can be treated successfully by removing the reservoir of the infection ${ }^{7,8}$. In the reachable literature, many studies have reported the systemic overuse of antibiotics in dentistry. In Turkey and Liverpool, $75 \%$ of patients ${ }^{9,10}$; in Germany, $43 \%$ of patients ${ }^{11}$; and in Britain, $30 \%$ of patients ${ }^{12}$ are prescribed antibiotics improperly. Therefore, AAPD guidelines underscore conservative antibiotic use and have set out principles that practitioners must follow when prescribing antibiotics to the paediatric population.

Previous studies have examined antibiotic use in dentistry but, up to now, only a few have examined antibiotic use in the paediatric population. The aim of this study was thus to evaluate Turkish dentists' approach to antibiotic use in paediatric patients. In particular, the dentists' adherence to available professional guidelines was investigated.

\section{Material and Methods}

\section{Questionnaires}

Questionnaires for this cross-sectional study were distributed to 206 dental practitioners, including general dentists, paediatric dentists and specialist dentists. The dental practitioners worked in Ministry of Health dental centres, universities of dentistry or private dental practices in seven different regions of Turkey. The researcher made questionnaire form was prepared according to the AAPD's 'Use of antibiotic therapy for pediatric dental patients' ${ }^{13}$ and 'Antibiotic prophylaxis for dental patients at risk for infection' guidelines ${ }^{14}$. In a pilot study, the questionnaire was pretested on 20 participants afterward excluded from the study. Electronic data software (Google Forms) was utilized for both the survey's construction and data collection.

The questionnaire contained information pertaining to the following: number of paediatric patients treated, number of prescribed antibiotics, most common antibiotic prescribed for aerobic and non-aerobic infections, clinical conditions under which antibiotics were prescribed and awareness of antibiotic prophylaxis. Although the questionnaire was anonymous, the respondents were requested to provide demographic information such as age and workplace. They were also requested to indicate whether they have attended any courses about antibiotic use.

\section{Statistical analysis}

The statistical analysis was done using the Statistical Package for the Social Sciences, version 23 (IBM Corp.,
Armonk, NY, USA). This study's demographic data, given as number and percentage, was tabularized. Categorical variables were described by frequency (percentage) and compared using the chi-square test. If the number of cells with an expected value less than 5 amounted to more than $20 \%$, the results were interpreted according to the "Pearson chi-square" instead of the "likelihood ratio chisquare". Significance was defined as $p$-value $<0.05$.

\section{Results}

Of the 1,012 surveys sent, 206 (20.3\%) were returned. Table 1 presents the practitioners' professional characteristics. The participants' professional experience rates were $35 \%$ for 10 or more years, $34 \%$ for $5-10$ years and $31.1 \%$ for 5 years or less. Of the respondents, $42.7 \%$ worked at universities, $30.6 \%$ at Ministry of Health dental centres and $26.7 \%$ at private dental practices. The majority of the participants were paediatric dentists $(45.1 \%)$ and general dentists (42.7\%). Approximately $84 \%$ of the respondents found their antibiotics training sufficient, while nearly $52 \%$ reported not having attended any antibiotic use courses.

Table 1. Professional characteristics

\begin{tabular}{lc}
\hline Variables & n (\%) \\
\hline Professional experience & \\
$>10$ & $72(35.0)$ \\
$5-10$ & $70(34.0)$ \\
$<5$ & $64(31.1)$
\end{tabular}

Workplace

University

Ministry of Health dental centres

Private dental practice

Dental specialty

General dentist

Paediatric dentist

Specialty dentist

Do feel you have enough antibiotics education?

Yes

No

Have you attended any antibiotic courses?

Yes

No

108 (52.4) 
Table 2. Practice characteristics

\begin{tabular}{|c|c|}
\hline Variables & $\mathrm{n}(\%)$ \\
\hline \multicolumn{2}{|l|}{ How many child patients visit you on average? } \\
\hline$<5$ a day & $93(45.1)$ \\
\hline $5-10$ a day & $40(19.4)$ \\
\hline$>10$ a day & $73(35.4)$ \\
\hline \multicolumn{2}{|c|}{$\begin{array}{l}\text { How many child patients do you prescribe antibiotics to on } \\
\text { average? }\end{array}$} \\
\hline None & $13(6.3)$ \\
\hline $1-4$ a day & $89(43.2)$ \\
\hline$\geq 4$ a day & $12(5.8)$ \\
\hline $1-5$ a week & $44(21.4)$ \\
\hline $1-4$ a month & $48(23.3)$ \\
\hline \multicolumn{2}{|c|}{ What is the first antibiotic you prefer for dental infections? } \\
\hline Penicillin & $195(94.7)$ \\
\hline Cephalosporin & $4(1.9)$ \\
\hline Macrolide & $2(1.0)$ \\
\hline Clindamycin & $5(2.4)$ \\
\hline Tetracycline & $-(-)$ \\
\hline \multicolumn{2}{|c|}{$\begin{array}{l}\text { What is your antibiotic of choice for dental infections of } \\
\text { anaerobic origin? }\end{array}$} \\
\hline Penicillin & $66(32.0)$ \\
\hline Cephalosporin & $8(3.9)$ \\
\hline Macrolide & $12(5.8)$ \\
\hline Clindamycin & $9(4.4)$ \\
\hline Metronidazole & $100(48.5)$ \\
\hline Tetracycline & $2(1.0)$ \\
\hline Penicillin + Metronidazole & $9(4.4)$ \\
\hline \multicolumn{2}{|l|}{ What is your antibiotic of choice for dental trauma? } \\
\hline Crown fracture & $4(1.9)$ \\
\hline Crown root fracture & $29(14.1)$ \\
\hline Root fracture & $39(18.9)$ \\
\hline Alveolar fracture & $114(55.3)$ \\
\hline Concussion & $9(4.4)$ \\
\hline Subluxation & $21(10.2)$ \\
\hline Extrusion & $65(31.6)$ \\
\hline Intrusion & $68(33)$ \\
\hline Primary dentition injury & $23(11.2)$ \\
\hline Avulsion & $148(71.8)$ \\
\hline Contaminated wound & $144(69.9)$ \\
\hline \multicolumn{2}{|c|}{ In which cases do you apply antibiotic prophylaxis? } \\
\hline $\begin{array}{l}\text { Prosthetic cardiac valve or prosthetic material } \\
\text { used for cardiac valve repair }\end{array}$ & $180(87.4)$ \\
\hline $\begin{array}{l}\text { Patient with shunts, indwelling vascular } \\
\text { catheters or other medical devices }\end{array}$ & $137(66.5)$ \\
\hline Previous infective endocarditis & $183(88.8)$ \\
\hline Unrepaired cyanotic congenital heart disease & $138(67)$ \\
\hline $\begin{array}{l}\text { Completely repaired congenital heart disease } \\
\text { with prosthetic material or device during the } \\
\text { first } 6 \text { months after the procedure }\end{array}$ & $176(85.4)$ \\
\hline $\begin{array}{l}\text { Cardiac transplantation recipients who develop } \\
\text { cardiac valvulopathy }\end{array}$ & $156(75.7)$ \\
\hline Autoimmune disease & $85(41.3)$ \\
\hline Sickle cell anaemia & $28(13.6)$ \\
\hline Chronic high-dose steroid usage & $49(23.8)$ \\
\hline Uncontrolled diabetes mellitus & $28(13.6)$ \\
\hline Bisphosphenate therapy & $65(31.6)$ \\
\hline History of total joint arthroplasty & $73(35.4)$ \\
\hline None & $3(1.5)$ \\
\hline \multicolumn{2}{|c|}{ For which procedures do you apply prophylaxis? } \\
\hline Manipulation of gingival tissue & $114(55.3)$ \\
\hline Manipulation of periapical tooth region & $141(68.4)$ \\
\hline Perforation of the oral mucosa & $111(53.9)$ \\
\hline $\begin{array}{l}\text { Routine anaesthetic injections through non- } \\
\text { infected tissue }\end{array}$ & $27(13.1)$ \\
\hline Placement of removable appliances & $-(-)$ \\
\hline Bleeding from trauma to the lips or oral mucosa & $89(43.2)$ \\
\hline Shedding of primary teeth & $11(5.3)$ \\
\hline None & $45(21.8)$ \\
\hline
\end{tabular}

The respondents' practice characteristics are shown in Table 2. The majority of the participants saw less than $5(45.1 \%)$ or more than $10(35.4 \%)$ children per day. Approximately $43 \%$ prescribed antibiotics to $1-4$ children per day. For dental infection management, the majority of dentists prescribed penicillin (94.7\%). Their first antibiotic choice for the presence of an anaerobic infection was metronidazole (48.5\%), followed by penicillin (32\%). For dental trauma, the most common antibiotic-prescribed cases were avulsion and contaminated wounds, following by alveolar fracture. In response to the questions on prescribing antibiotics for cases requiring prophylaxis, $88.8 \%$ of the respondents would prescribe them for previous infective endocarditis, $87.4 \%$ for prosthetic cardiac valve or cardiac valve repair material and $85.4 \%$ for completely repaired congenital heart disease with prosthetic material/devices for the first 6 months after the procedure. The respondents' most common procedure choices in the presence of antibiotic prophylaxis were manipulation of the periapical teeth region $(68.4 \%)$, manipulation of gingival tissue (55.3\%), perforation of the oral mucosa $(53.9 \%)$ and bleeding from trauma to the lips or oral mucosa $(43.2 \%)$.

The participants prescribed antibiotics as their first choice for dental infections and dental infections of anaerobic origin, with no significant differences between professional experience or dental specialty $(p>0.05$; Tables 3). Practitioners from Ministry of Health dental centres' significantly differed from all groups in preferring the antibiotic cephalosporin for dental infections of anaerobic origin $(p<0.05$; Table 3$)$.

Table 4 shows a list of other non-clinical criteria that influenced the respondents' antibiotic prescriptions. In total, $67.3 \%$ of the participants did not prescribe antibiotics due to non-clinical conditions. Still, the presence of a fistula in the gingiva was the most common reason for prescribing antibiotics (20.4\%). About $12.6 \%$ prescribed antibiotics when busy with appointments and $10.7 \%$ when the diagnosis was uncertain. Only a few practitioners prescribed antibiotics per parents' expectations for a prescription, when a patient was consulted and when the only symptom was pain. 
Table 3. Percentage of practitioners' antibiotic preferences according to professional characteristics

\begin{tabular}{|c|c|c|c|}
\hline & $<5$ years & $5-10$ years & $>10$ years \\
\hline \multicolumn{4}{|l|}{ Dental infections* } \\
\hline Penicillin & 96.9 & 98.6 & 88.9 \\
\hline Cephalosporin & 0 & 1.4 & 4.2 \\
\hline Macrolide & 0 & 0 & 2.8 \\
\hline Clindamycin & 3.1 & 0 & 4.2 \\
\hline \multicolumn{4}{|c|}{ Dental infections of anaerobic origin** } \\
\hline Penicillin & 43.8 & 24.3 & 29.2 \\
\hline Cephalosporin & 1.6 & 5.7 & 4.2 \\
\hline Macrolide & 3.1 & 10.0 & 4.2 \\
\hline Clindamycin & 1.6 & 7.1 & 4.2 \\
\hline Metronidazole & 43.8 & 47.1 & 54.2 \\
\hline Tetracycline & 1.6 & 0 & 1.4 \\
\hline \multirow[t]{2}{*}{ Penicillin + Metronidazole } & 4.7 & 5.7 & 2.8 \\
\hline & University & $\begin{array}{l}\text { Ministry of Health dental } \\
\text { centre }\end{array}$ & Private dental practice \\
\hline \multicolumn{4}{|l|}{ Dental infections ${ }^{* * *}$} \\
\hline Penicillin & 97.7 & 93.7 & 90.9 \\
\hline Cephalosporin & 0 & 4.8 & 1.8 \\
\hline Macrolide & 0 & 0 & 3.6 \\
\hline Clindamycin & 2.3 & 1.6 & 3.6 \\
\hline \multicolumn{4}{|c|}{ Dental infections of anaerobic origin } \\
\hline Penicillin & 30.7 & 36.5 & 29.1 \\
\hline Cephalosporin & 1.1 & $11.1^{\dagger}$ & 0 \\
\hline Macrolide & 5.7 & 9.5 & 1.8 \\
\hline Clindamycin & 3.4 & 3.2 & 7.3 \\
\hline Metronidazole & 53.4 & 33.3 & 58.2 \\
\hline Tetracycline & 0 & 3.2 & 0 \\
\hline \multirow[t]{2}{*}{ Penicillin + Metronidazole } & 5.7 & 3.2 & 3.6 \\
\hline & General dentist & Paediatric dentist & Specialty dentist \\
\hline \multicolumn{4}{|l|}{ Dental infections } \\
\hline Penicillin & 92.0 & 96.8 & 96 \\
\hline Cephalosporin & 3.4 & 1.1 & 0 \\
\hline Macrolide & 1.1 & 1.1 & 0 \\
\hline Clindamycin & 3.4 & 1.1 & 4 \\
\hline \multicolumn{4}{|c|}{ Dental infections of anaerobic origin } \\
\hline Penicillin & 36.4 & 29.0 & 28.0 \\
\hline Cephalosporin & 8 & 1.1 & 0 \\
\hline Macrolide & 4.5 & 6.5 & 8.0 \\
\hline Clindamycin & 4.5 & 4.3 & 4.0 \\
\hline Metronidazole & 42.0 & 53.8 & 52.0 \\
\hline Tetracycline & 2.3 & 0 & 0 \\
\hline Penicillin + Metronidazole & 2.3 & 5.4 & 8 \\
\hline
\end{tabular}

*No differences among specialty groups (Pearson's chi-square test $=10.020 ; p=0.124$ )

**No differences among specialty groups (Pearson's chi-square test $=13.936 ; p=0.305$ )

$* * *$ No differences among specialty groups (Pearson's chi-square test $=10.483 ; p=0.106$ )

$\dagger$ Significantly different from all groups $(p<0.01)$

* No differences among specialty groups (Pearson's chi-square test $=3.516 ; p=0.742$ )

『No differences among specialty groups (Pearson's chi-square test $=13.933 ; p=0.305$ ) 
Table 4. Non-clinical criteria considerations

\begin{tabular}{ll}
\hline Variables & $\mathbf{n}(\mathbf{\%})$ \\
\hline Parents' expectations for a prescription & $12(5.8)$ \\
Busy appointments & $26(12.6)$ \\
Patient consultation & $7(3.4)$ \\
Diagnosis uncertain & $22(10.7)$ \\
The only symptom is pain & $7(3.4)$ \\
The only symptom is fistula & $42(20.4)$ \\
None & $140(67.3)$ \\
\hline
\end{tabular}

\section{Discussion}

In the accessible literature, there is no study about the use of antibiotics to treat dental infections in Turkish children, so this study was planned to address this research gap. The proportion of dentists who had attended a course or symposium on antibiotic treatment was equal to those who had not $(47.6 \%)$. This rate is higher than in other studies ${ }^{15}$. This has been associated with an increase in both the number of antibiotic courses and the interest in these courses, as recently, due attention has been drawn to antibiotic resistance.

The gold standard for the treatment of dental infections has been penicillin until now due to its low toxicity, efficacy in polymicrobial infections, relatively narrow spectrum for bacteria, especially in endodontic infections, and low cost $\mathrm{t}^{16-18}$. Penicillin was the most frequently prescribed antibiotic (94.7\%) for dental infections that required an antibiotics regime, followed by clindamycin and cephalosporin, respectively. The reason for choosing clindamycin is thought to be patients with a penicillin allergy. Regardless of the participants' ages, workplaces or experience, their first antibiotic choice was penicillin. The most preferred antibiotic in dental infections caused by harbour anaerobic organisms were metronidazole (48.5\%) and penicillin (32\%). However, metronidazole alone has a low efficacy for odontogenic resistant infections ${ }^{17-19}$. Concomitant amoxicillin and metronidazole use is well-supported in the literature, especially in cases where it is thought to contain anaerobes ${ }^{20,21}$. The AAPD indicates that penicillin remains an empirical option for odontogenic infections, though it has also suggested that additional adjuvant antimicrobial therapy (i.e. metronidazole) should be considered in cases of anaerobic bacterial involvement ${ }^{13}$. In our study, very few participants combined antibiotics. We assume that this forms a difference in the prescription of antibiotics between paediatric dentists and other dentists, as the first group has more comprehensive education on children. Still, we concluded that additional vocational training is not a factor that contributes to compliance with prescription guidelines; similar findings were reported by Vasudavan et al. ${ }^{2}$ and Cherry et al. ${ }^{22}$.

The AAPD and IADT approve the use of oral antibiotics in instances such as avulsed permanent tooth with an open or closed apex and concomitant soft tissue injuries, and when dictated by the patient's medical status $^{13,23}$. In our study, avulsion and contaminated tissue injuries were the most common trauma cases eliciting antibiotic prescriptions. However, it is quite often to see antibiotic use in other dental trauma cases. This study's results thus indicate a potential problem in how clinicians use antibiotics for dental trauma in children.

Infective endocarditis is an uncommon complication that can be life-threatening due to the presence of bacteraemia. In a multicentre study of American children's hospitals, the incidence of paediatric admissions due to infective endocarditis was reported as between 0.05 and 0.12 cases per 1,000 admissions from 2003 to $2010^{14}$. In our study, the participants recommended antibiotic prophylaxis for invasive dental procedures in the cardiac conditions given in the table. Except for patients with total joint prosthesis, other patients in this table are of high-risk and should be considered for prophylaxis, although there is insufficient data to support its use. Still, historically total joint arthroplasty does not require antibiotic use $^{14}$. Looking at the study's results, we found that the application of antibiotic prophylaxis in the risk groups was insufficient. While the AAPD requires antibiotic prophylaxis for all dental procedures involving treatment of the gingiva tissue, periapical teeth region or perforation of the oral mucosa, it does not require antibiotic prophylaxis in the other procedures in the table. However, the number of participants who apply antibiotics in the necessary dental procedures was poor. These results support the need to publish clearer guidelines for antibiotic prophylaxis.

It is worth emphasizing that the majority of the respondents would not prescribe antibiotics for non-clinical criteria considerations, such as patient consultations, when the only symptom is pain or when parents expect a prescription. A significant percentage of especially toothache is due to acute and chronic pulpal infections that require surgical intervention rather than antibiotics $^{24}$. A small fraction of the respondents would prescribe antibiotics when a diagnosis was uncertain. This is due to the fear that a delayed response can lead to serious consequences. There were also participants who found empirical antibiotic therapy suitable when they were busy with appointments, regardless of whether such a drug was required. We assume that this may be related to high patient density. Surprisingly, though, about $20.4 \%$ of the patients would prescribe antibiotics when the only symptom was fistula, showing that some participants act inconsistently with the practices recommended by professional guidelines. Unless there is systemic 
involvement, effective drainage and elimination of the infection agent sufficiently manage simple abscesses and fistulas ${ }^{13}$. In addition, because of the lack of effective circulation in a necrotic pulp or abscess, the effectiveness of oral antibiotics as a sole treatment for an odontogenic infection is highly arguable ${ }^{16}$. Konde et al. ${ }^{25}$ reported that of practitioners who prescribed antibiotics, $34 \%$ did so to postpone appointments, $68 \%$ required special treatment and $35 \%$ at the coercion of parents. The study underlines that dentists are not worried about reducing this serious problem, although they are aware of antibiotic resistance. Another study from Kuwait emphasized that antibiotic abuse may be due to the heavy workload and personal comfort of dentists in the country ${ }^{15}$. The fact that nonclinical antibiotic use in our study data was less than other studies can be explained by the increased awareness of dentists and patients about antibiotic resistance.

We need to consider this study's results in light of some limitations. The study's cross-sectional nature limits its ability to make causal inferences. The dentists who chose to respond to the survey serving as representatives of all paediatric dentists in Turkey is another limitation. The respondents may also have been informed about the use of antibiotics. Moreover, the dentists' survey answers may not fully reflect their actual practice; given this limitation, the dentists' compliance with antibiotic use guidelines may be worse than actually reported.

\section{Conclusions}

This study's results provide preliminary data on the extent to which Turkish dentists follow professional guidelines for prescribing antibiotics for paediatric dental infections. This study shows a low adherence among all dentists to follow these guidelines. Clearer, more specific guidelines and increased post-graduate education can, however, reduce the negative consequences of overprescribed antibiotics.

\section{References}

1. Suda KJ, Hicks LA, Roberts RM, Hunkler RJ, Danziger LH. A national evaluation of antibiotic expenditures by healthcare setting in the United States, 2009. J Antimicrob Chemother, 2013;68:715-718.

2. Vasudavan S, Grunes B, Mcgeachie J, Sonis AL. Antibiotic Prescribing Patterns Among Dental Professionals In Massachusetts. Pediatr Dent, 2019;41:25-30.

3. Kuriyama T, Karasawa T, Nakagawa K, Saiki Y, Yamamoto E, Nakamura S. Bacteriological features and antimicrobial susceptibility in isolates from orofacial odontogenic infections. Oral Surg Oral Med Oral Pathol Oral Radiol Endod, 2000;90:600-608.
4. Pallasch TJ. Antibiotic resistance. Dent Clin North Am, 2003;47:623-639.

5. Durkin MJ, Hsueh K, Sallah YH, Feng Q, Jafarzadeh $\mathrm{SR}$, Munshi KD, et al. An evaluation of dental antibiotic prescribing practices in the United States. J Am Dent Assoc, 2017;148:878-886.

6. Haque M, Sartelli M, Haque SZ. Dental Infection and Resistance-Global Health Consequences. Dent J (Basel), 2019;7:22.

7. Wagner JG. Relevant pharmacokinetics of antimicrobial drugs. Med Clin North Am, 1974;58:479-492.

8. Khan K, Muennig P, Behta M, Zivin JG. Global drugresistance patterns and the management of latent tuberculosis infection in immi- grants to the United States. N Engl J Med, 2002;347:1850-1859.

9. Dailey YM, Martin MV. Are antibiotics being used appropriately for emergency dental treatment? Br Dent J, 2001;191:391-393.

10. Kandemir S, Ergul N. Grievances in cases using anti- biotics due to orodental problems and assessment of the need for antibiotics. Int Dent J, 2000;50:73-77.

11. Mikulaschenk P, Rechmann P, Strassburg M. Prescription habits of antibiotics in the dental practice. Dtsch Zahnarztl Z, 1985;40:351-353.

12. Thomas DW, Satterthwaite J, Absi FC, Lewis MA, Shepherd JP. Antibiotic prescription for acute dental conditions in the primary care setting. $\mathrm{Br}$ Dent $\mathrm{J}$, 1996;181:401-404.

13. American Academy of Pediatric Dentistry. Use of Antibiotic Therapy for Pediatric Dental Patients. Pediatr Dent, 2018;40:383-385.

14. American Academy of Pediatric Dentistry. Antibiotic Prophylaxis for Dental Patients at Risk for Infection. Pediatr Dent, 2018;40:386-391.

15. Salako NO, Rotimi VO, Adib SM, Al-Mutawa S. Pattern of antibiotic prescription in the management of oral diseases among dentists in Kuwait. J Dent, 2004;32:503-509.

16. Swift JQ, Gulden WS. Antibiotic therapy: managing odontogenic infections. Dent Clin N Am, 2002;46:623-633.

17. Baumgartner JC, Xia T. Antibiotic susceptibility of bacteria associated with endodontic abscesses. J Endod, 2003;29:44-47.

18. Khemaleelakul S, Baumgartner JC, Pruksakorn S. Identification of bacteria in acute endodontic infections and their antimicrobial susceptibility. Oral Surg Oral Med Orl Pathol, 2002;94:746-755.

19. Brook I. Microbiology and management of endodontic infections in children. J Clin Pediatric Dent, 2003;28:13-17.

20. Salinas M, Riu N, Berini L, Escoda C. Antibiotic susceptibility of the bacteria causing odontogenic infections. Med Oral Patol Oral Cir Bucal, 2006;11:e70-e75.

21. Pallasch TJ. Pharmacokinetic principles of antimicrobial therapy. Periodonol 2000, 1996;10:5-11.

22. Cherry WR, Lee JY, Shugars DA, White RP Jr, Vann WF Jr. Antibiotic use for treating dental infections in children: a survey of dentists' prescribing practices. J Am Dent Assoc, 2012;143:31-38.

23. Fouad AF, Abbott PV, Tsilingaridis G, Cohenca N, Lauridsen E, Bourguignon C, et al. International Association of Dental Traumatology guidelines for the management of traumatic dental injuries: 2. Avulsion of permanent teeth. Dent Traumatol, 2020;36:331-342. 
24. Longman LP, Preston AJ, Martin MV, Wilson NH. Animal Rights Statement: None required. Endodontics in the adult patient: The role of antibiotics. J Dent, 2000;28:539-548.

25. Konde S, Jairam LS, Peethambar P, Noojady SR, Kumar NC. Antibiotic overusage and resistance: A cross-sectional survey among pediatric dentists. J Indian Soc Pedod Prev Dent, 2016;34:145-151.

Conflict of Interests: Nothing to declare.

Financial Disclosure Statement: Nothing to declare.

Human Rights Statement: All the procedures on humans were conducted in accordance with the Helsinki Declaration of 1975, as revised 2000. Consent was obtained from the patient/s and approved for the current study by national ethical committee.

Received on September 23, 2020.

Revised on November 20, 2020.

Accepted on November 25, 2020.

Correspondence:

Tugba Yigit

Department of Pediatric Dentistry

Faculty of Dentistry

Usak University, Usak, Turkey

e-mail: tugba.yigit@usak.edu.tr 